\title{
Formaldehyde Selectivity in Methanol Partial Oxidation on Silver: Effect of Reactive Oxygen Species, Surface Reconstruction, and Stability of Intermediates
}

\author{
Mustafa Karatok, Mehmet Gokhan Sensoy, Evgeny I. Vovk, Hande Ustunel, Daniele Toffoli, \\ and Emrah Ozensoy*
}

Cite This: ACS Catal. 2021, 11, 6200-6209

Read Online

ACCESS | Lلll Metrics \& More | 回 Article Recommendations | st Supporting Information

ABSTRACT: Selective oxidation reactions on heterogeneous silver catalysts are essential for the mass production of numerous industrial commodity chemicals. However, the nature of active oxygen species in such reactions is still debated. To shed light on the role of different oxygen species, we studied the methanol oxidation reaction on $\mathrm{Ag}(111)$ single-crystal model catalyst surfaces containing two dissimilar types of oxygen (electrophilic, $\mathrm{O}_{\mathrm{e}}$ and nucleophilic, $\mathrm{O}_{\mathrm{n}}$ ). X-ray photoelectron spectroscopy and low energy electron diffraction experiments suggested that the atomic structure of the $\mathrm{Ag}(111)$ surface remained mostly unchanged after accumulating low $\mathrm{O}_{\mathrm{e}}$ coverage at $140 \mathrm{~K}$. Temperature-programmed reaction spectroscopic investigation of

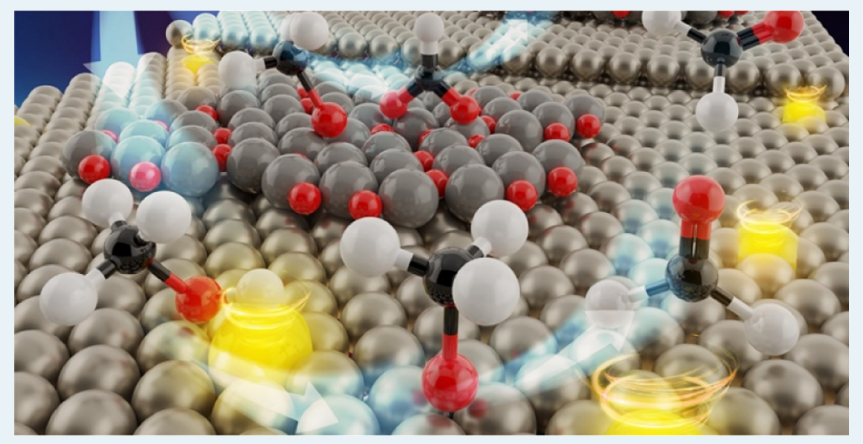
low coverages of $\mathrm{O}_{e}$ on $\mathrm{Ag}(111)$ revealed that $\mathrm{O}_{\mathrm{e}}$ was active for methanol oxidation on $\mathrm{Ag}(111)$ with a high selectivity toward formaldehyde $\left(\mathrm{CH}_{2} \mathrm{O}\right)$ production. High surface oxygen coverages, on the other hand, triggered a reconstruction of the $\mathrm{Ag}(111)$ surface, yielding $\mathrm{Ag}$ oxide domains, which catalyzes methanol total oxidation to $\mathrm{CO}_{2}$ and decreases the formaldehyde selectivity. This important finding indicates a trade-off between $\mathrm{CH}_{2} \mathrm{O}$ selectivity and methanol conversion, where $93 \% \mathrm{CH}_{2} \mathrm{O}$ selectivity can be achieved for an oxygen surface coverage of $\theta_{\mathrm{O}}=0.08 \mathrm{ML}(\mathrm{ML}=$ monolayer $)$ with moderate methanol conversion, while methanol conversion could be boosted by a factor of $\sim 4$ for $\theta_{\mathrm{O}}=0.26 \mathrm{ML}$ with a suppression of $\mathrm{CH}_{2} \mathrm{O}$ selectivity to $50 \%$. Infrared reflection absorption spectroscopy results and density functional theory calculations indicated that $\mathrm{Ag}$ oxide contains dissimilar adsorption sites for methoxy intermediates, which are also energetically less stable than that of the unreconstructed $\mathrm{Ag}(111)$. The current findings provide important molecular-level insights regarding the surface structure of the oxidized $\mathrm{Ag}(111)$ model catalyst directly governing the competition between different reaction pathways in methanol oxidation reaction, ultimately dictating the reactant conversion and product selectivity.

KEYWORDS: methanol oxidation, selective catalytic oxidation, silver catalyst, formaldehyde, atomic oxygen

\section{INTRODUCTION}

Silver is one of the essential metals used in various selective catalytic oxidation (SCO) reactions carried out in the chemical industry. Ethylene oxidation yielding ethylene oxide $\left(\mathrm{CH}_{2} \mathrm{OCH}_{2}\right)$ and methanol oxidation producing formaldehyde $\left(\mathrm{CH}_{2} \mathrm{O}\right)$ are among the most prominent SCO reactions occurring on heterogeneous silver catalysts. ${ }^{1,2}$ These products are used in the synthesis of numerous commodity chemicals and are also utilized directly in other chemical processes. For example, ethylene oxide is used to produce pharmaceuticals, detergents, and plastics, while formaldehyde is heavily consumed to make a variety of chemicals for the construction, automotive, and furniture sectors. ${ }^{1-4}$ Recent reports indicate that the global annual consumption of ethylene oxide and formaldehyde is over 35 million tons, each. ${ }^{2,3,5}$ The annual global production of these chemicals is estimated to grow monotonically due to the increasing demand by the chemical industry. Thus, the SCO continues to be an active field of not only applied but also fundamental research. ${ }^{4-7}$

A critical challenge in heterogeneous SCO is to understand the nature of the oxygen species and their catalytic role under reaction conditions. Particularly, distinguishing various oxygen species responsible for the partial and complete oxidation pathways is essential in order to design novel heterogeneous catalysts with high reactivity and selectivity. Along these lines,

Received: January 25, 2021

Revised: April 9, 2021

Published: May 7, 2021

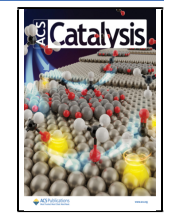


there exist immense efforts in the literature focusing on the identification of different oxygen species that can be generated on model catalytic Ag surfaces, ${ }^{8-24}$ as well as their chemical interactions with reactants such as ethylene $e^{25-27}$ and methanol. $^{28-32}$ In former studies, two different types of oxygen species were identified via X-ray photoelectron spectroscopy (XPS) revealing distinct electronic properties. ${ }^{16,17,27}$ The $O$ 1s XPS signals for these species were determined to be at 530.3 and $528.3( \pm 0.2) \mathrm{eV}$ and were attributed to the so-called "electrophilic $\left(\mathrm{O}_{\mathrm{e}}\right)$ " and "nucleophilic $\left(\mathrm{O}_{\mathrm{n}}\right)$ ” oxygen species, respectively. While nucleophilic oxygen is commonly considered to be a strongly bonded oxygen atom in $\mathrm{Ag}$ oxide structures, the precise nature of the electrophilic oxygen is still being debated. ${ }^{16,22,33,34}$ Moreover, the roles of these dissimilar oxygen species in the SCO are yet to be understood at the molecular level.

Apart from the electronic properties, the thermal stability of the oxygen species is also a key factor in catalytic oxidation selectivity. Former ultra-high vacuum (UHV) studies showed that the atomic oxygen is stable on the $\operatorname{Ag}(111)$ surface only up to $c a .600 \mathrm{~K}$ and cannot be present on the model catalyst surfaces during the methanol oxidation reaction conditions involving elevated temperatures such as ca. $900 \mathrm{~K} .^{9,35}$ Instead, surface-embedded atomic oxygen $\left(\mathrm{O}_{\gamma}\right)$, which is stable up to $900 \mathrm{~K}$ was suggested to be the reactive oxygen species in methanol oxidation. ${ }^{18,30,36}$ In contrast, a computational microkinetic modeling study argued that surface atomic oxygen species could be present at $900 \mathrm{~K}$ under oxygen pressures above $1 \mathrm{kPa}^{37}$ Furthermore, recent studies revealed evidence that "kinetically trapped" or metastable oxygen species can form under reaction conditions and become decisive in product selectivity. ${ }^{38,39}$ Such discrepancies in the literature clearly indicate that there are still unresolved fundamental questions regarding the nature of oxygen species on catalytic silver surfaces and their role in the partial oxidation reactions.

Former investigations on the nature of oxygen species in the SCO over heterogeneous silver catalysts were mostly performed under oxygen-rich conditions. ${ }^{16,40,41}$ Such reactivity studies typically assumed that a $\mathrm{Ag}$ oxide surface with a $p(4 \times$ 4) structure was the dominant phase under reaction conditions because this was the dominant phase at oxygen pressures close to the ambient conditions. ${ }^{20}$ In contrast, formaldehyde production in the industry is typically carried out under methanol-rich conditions (e.g., $\left.\mathrm{CH}_{3} \mathrm{OH} / \mathrm{O}_{2}=2.0-2.5\right){ }^{31,42} \mathrm{~A}$ former in situ Raman study conducted at atmospheric pressure and elevated temperatures showed that the polycrystalline silver existed in a reduced (i.e., metallic) state during methanol oxidation. ${ }^{43}$ A recent computational study also showed that a low oxygen surface coverage $(<0.2 \mathrm{ML}, \mathrm{ML}=$ monolayer $)$ was needed for high formaldehyde selectivity in methanol oxidation. ${ }^{6}$ These studies suggest that the precise control of the low surface coverage oxygen species on the catalyst surface is essential in the SCO of methanol.

While methanol oxidation reaction on $p(4 \times 4)$ reconstructed $\mathrm{Ag}$ oxide surfaces on the $\operatorname{Ag}(111)$ substrate was investigated in a former report, ${ }^{44}$ the literature lacks a comparative study examining methanol oxidation on atomic oxygen-containing $\mathrm{Ag}(111)$ model catalyst surfaces [O/ $\mathrm{Ag}(111)]$ and $\mathrm{Ag}$ oxide surfaces. In the current work, we focus on these two dissimilar surface states of the silver model catalyst surfaces. Along these lines, we present experimental findings indicating that various types of adsorbed methoxy intermediates having different stabilities can be generated on $\mathrm{O} / \mathrm{Ag}(111)$ and $\mathrm{Ag}$ oxide domains during methanol oxidation reaction. We used ozone decomposition as an effective oxygen delivery method to prepare $\mathrm{O} / \mathrm{Ag}(111)$ and $\mathrm{Ag}$ oxide model catalyst surfaces, enabling the precise control of the quantity of the oxygen species introduced on the model catalyst surface particularly at low ozone partial pressures (e.g., $<5 \times 10^{-10}$ Torr). Chemisorbed oxygen atom formation with this method was previously reported on various model catalyst surfaces such as $\mathrm{Au}(111)^{45}$ and $\mathrm{Pt}(111)^{46}$ under UHV conditions. This method also precludes the use of high-pressure adsorbate exposures which may lead to excessive surface oxygen coverages and/or deposition of unwanted contaminants on the model catalyst surface. In contrast to the elevated/ambient pressure $\mathrm{O}_{2}$ experiments, the currently employed oxygen delivery protocol allows the preparation of unreconstructed $\mathrm{O} /$ $\mathrm{Ag}(111)$ surfaces possessing very low (e.g., $0.04 \mathrm{ML}$ ) oxygen adsorbate coverages. Because the surface reconstruction of $\mathrm{Ag}(111)$ and formation of silver oxide domains typically start at oxygen coverages above $0.05 \mathrm{ML},{ }^{47}$ it is challenging to study unreconstructed $\mathrm{O} / \mathrm{Ag}(111)$ surfaces under elevated pressures, rendering the currently utilized oxygen delivery protocol preferable.

\section{METHODS}

Experimental Details. All experiments were performed in a UHV chamber with a background pressure of $<5.0 \times 10^{-10}$ Torr which was equipped with low-energy electron diffraction (LEED; custom-made), infrared reflection absorption spectroscopy (IRAS; Bruker Tensor37 with custom design external IR optics and a tailor-made $\mathrm{N}_{2}$ purge box, $4 \mathrm{~cm}^{-1}$ resolution, 100 scans, $10 \mathrm{kHz}$ scanner velocity, and mercury cadmium telluride IR detector), XPS (Riber nonmonochromatized Al $\mathrm{K} \alpha \mathrm{X}$-ray excitation, $300 \mathrm{~W}$, Riber EA150 electron energy analyzer), and temperature-programmed reaction spectroscopy (TPRS) capabilities.

The $\operatorname{Ag}(111)$ single crystal (Matech $\mathrm{GmbH}, 10 \mathrm{~mm}$ diameter $\times 1 \mathrm{~mm}$ thick disk, $>99.9999 \%$ purity) was affixed on Ta wires, through which the sample could be resistively heated to $1073 \mathrm{~K}$. The cooling of the sample was achieved via a liquid nitrogen reservoir located inside the sample manipulator probe holding the $\operatorname{Ag}(111)$ single crystal. The temperature of the sample was measured using a K-type thermocouple spot-welded on the lateral facet of the $\operatorname{Ag}(111)$ disk. The sample was cleaned by cycles of $\mathrm{Ar}^{+}$sputtering $[\operatorname{Ar}(\mathrm{g})$, Linde AG, $99.999 \%$ purity] with a sputter gun (LK Technologies, NGI3000, $1.5 \mathrm{kV} \times 15 \mathrm{~mA}$ ) and repetitive cycles of $\mathrm{O}_{3}$ treatment at room temperature, followed by annealing to $800 \mathrm{~K}$ for $5 \mathrm{~min}$.

TPRS experiments were performed by using a quadrupole mass spectrometer (QMS; Ametek Dycor Dymaxion DM200) and a proportional-integral-derivative controlled linear sample heater (Heatwave, model 101303). All of the TPRS experiments were performed with a heating rate of $1 \mathrm{~K} / \mathrm{s}$, a 70 eV QMS electron ionization energy, and a $30 \mathrm{~ms}$ dwell time for each desorption channel. Methanol (Sigma-Aldrich, 99.9\% purity) was purified by several freeze-pump-thaw cycles in a glass bulb connected to a gas manifold and dosed onto the sample via a leak valve. In order to eliminate the molecular (undissociated) methanol adsorption and generate predominantly methoxy species with a high surface coverage on $\mathrm{O} /$ $\operatorname{Ag}(111)$, in each of the TPRS experiments, 0.06 Langmuir (1 $\mathrm{L}=10^{-6}$ Torr $\times \mathrm{s}^{-1}$ ) of methanol [i.e., corresponding to 2 

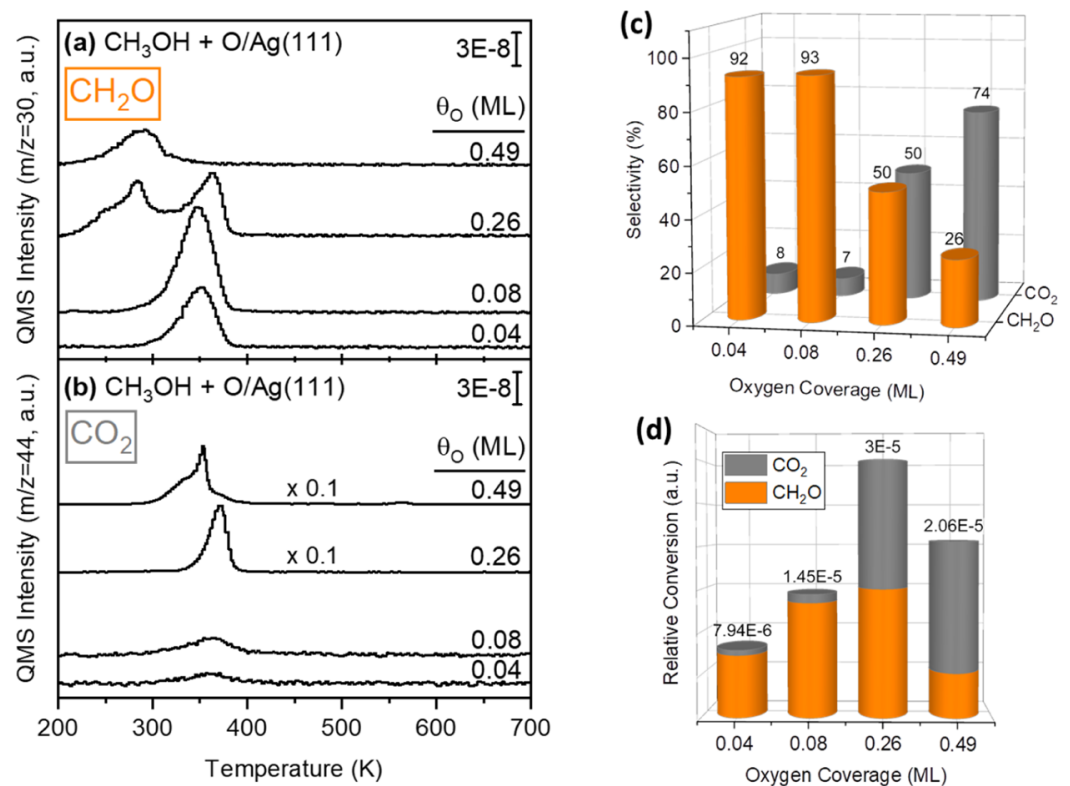

Figure 1. Temperature-programmed reaction profiles for (a) formaldehyde and (b) carbon dioxide in the catalytic methanol oxidation on $\mathrm{O} /$ $\mathrm{Ag}(111)$ surfaces as a function of oxygen coverage. In all cases, oxygen was delivered on $\mathrm{Ag}(111)$ via ozone exposure at $140 \mathrm{~K}$, followed by $0.06 \mathrm{~L}$ methanol exposure at $200 \mathrm{~K}$. (c) Catalytic selectivity of $\mathrm{Ag}(111)$ toward formaldehyde and carbon dioxide as a function of oxygen coverage, calculated using the integrated desorption signals in (a) and (b). (d) Total catalytic methanol conversion represented as the combined amount of formaldehyde and carbon dioxide produced. The details of the quantification procedure are provided in the Supporting Information Section 1.

monolayer equivalent, monolayer equivalent (MLE) of methanol dose at $100 \mathrm{~K}$ ] was introduced at $200 \mathrm{~K}$ on $\mathrm{O} /$ $\operatorname{Ag}(111)$. In the TPRS experiments, $m / z=2,18,28,29,30,31$, 32,44 , and 46 desorption channels were simultaneously monitored (see Supporting Information, SI Section 1, Figure S1).

The ozone decomposition method was used for the delivery of atomic oxygen on the $\mathrm{Ag}(111)$ model catalyst surface under UHV conditions. Ozone was produced by a commercial ozone generator (Genozon, GN-G1001S, Turkey) and directly dosed on the sample through a leak valve. Additional details regarding the ozone delivery system can be found elsewhere. ${ }^{48}$ Oxygen coverages in this study were calculated based on oxygen temperature-programmed desorption (TPD) experiments on the clean $\operatorname{Ag}(111)$ surface, which was discussed in detail in one of our former reports. ${ }^{35}$ In that report, the oxygen desorption signal converged to saturation at $550 \mathrm{~K}$, and the saturation coverage was designated as 1 MLE. In former studies, oxygen coverage for a single layer of silver oxide with various oxide structures [i.e., $p(4 \times 4), p(4 \times 5 r 3)]$ was calculated to be $0.375 \mathrm{ML} .{ }^{13}$ Thus, in the current work, the saturation oxygen coverage obtained at the top layer of $\mathrm{Ag}(111)$ in the oxygen TPD experiments ${ }^{35}$ was assumed to be $0.375 \mathrm{ML}$ and used as a reference.

Computational Methods. Density functional theory (DFT) calculations were carried out in order to determine the adsorption energies of various relevant species on two different types of oxygen-containing $\mathrm{Ag}(111)$ single crystal surface models. The first model comprised a $\operatorname{Ag}(111)$ surface, where $\mathrm{O}$ atoms were introduced as adatoms. On this surface, we investigated methanol, methoxy, formaldehyde, and formate adsorption properties as a function of $\mathrm{O}$ coverage. The second model was a surface oxide on $\mathrm{Ag}(111)$ with a $p(4$ $\times 4)$ reconstruction as proposed by Schmid et al. ${ }^{49}$ and is hereafter referred to as $p(4 \times 4)-\mathrm{O} / \mathrm{Ag}(111)$.
The DFT calculations were performed using the Vienna $\mathrm{Ab}$ Initio Simulation Package (VASP) code suite ${ }^{50}$ based on the projector-augmented wave formalism ${ }^{50,51}$ with the GGA-PBE (generalized gradient approximation - Perdew--Burke--Ernzerhof $)^{52}$ functional to describe electron exchange and correlation. A kinetic energy cutoff of $400 \mathrm{eV}$ was used to truncate the plane wave expansion. The Tkatchenko-Scheffler (TS) correction $^{53}$ was used to model the van der Waals interactions.

The clean and O-decorated $\operatorname{Ag}(111)$ surfaces were both modeled using a 5-layer $3 \times 3$ slab with a vacuum distance of at least $14 \AA$ between adjacent periodic images. The repeating simulation cell for the $p(4 \times 4)-\mathrm{Ag}(111)-\mathrm{O}$ reconstruction was modeled using a four-layer $4 \times 4$ slab. In both slab models, the bottom two layers were kept fixed during geometric optimization to mimic bulk behavior. The positions of all mobile atoms were optimized until all atomic forces were less than $0.01 \mathrm{eV} / \AA$. Monkhorst-Pack ${ }^{54} k$-point sets of $7 \times 7 \times 1$ and $3 \times 3 \times 1$ points were used for $\operatorname{Ag}(111)$ and $p(4 \times 4)-$ $\mathrm{Ag}(111)-\mathrm{O}$ surfaces, respectively.

Adsorption energies $\left(E_{\text {ads }}\right)$ of the molecules were obtained using the equation

$$
E_{\mathrm{ads}}=E_{\mathrm{tot}}-E_{\mathrm{surf}}-E_{\mathrm{mol}}
$$

where $E_{\text {tot }} E_{\text {surf }}$ and $E_{\text {mol }}$ denote the total energy of the system, the energy of the surface, and the energy of the molecule in the gas phase, respectively. According to eq 1, negative adsorption energies correspond to exothermic adsorption.

\section{RESULTS AND DISCUSSION}

Methanol Reactivity on $\mathbf{A g}(111)$ and $\mathrm{O} / \mathrm{Ag}(111)$. As an initial control experiment, the reactivity of the clean $\operatorname{Ag}(111)$ surface toward methanol was investigated using TPD, where various coverages of methanol were dosed on clean $\operatorname{Ag}(111)$ at $100 \mathrm{~K}$ (Supporting Information, SI Section 2, Figure S2). In accordance with the literature, ${ }^{55}$ in the absence of oxygen, 
methanol was found to adsorb and desorb reversibly from the clean $\operatorname{Ag}(111)$ surface in a molecular fashion without dissociation at $T \leq 170 \mathrm{~K}$. Clearly, the $\operatorname{Ag}(111)$ surface was incapable of initiating methanol bond activation in the absence of the oxygen species. Molecular methanol adsorption on clean $\operatorname{Ag}(111)$ was also verified with IRAS and is discussed in detail below.

However, the interaction of methanol with oxygencontaining $\mathrm{Ag}(111)$ surfaces $[\mathrm{O} / \mathrm{Ag}(111)]$ generated formaldehyde and carbon dioxide in TPRS experiments as the SCO and total oxidation products, respectively (Figures 1 and S1). In the current TPRS experiments, methanol exposure at $200 \mathrm{~K}$ on $\mathrm{O} / \mathrm{Ag}(111)$ surfaces containing 0.04 or $0.08 \mathrm{ML}$ of oxygen mainly yielded formaldehyde (Figure $2 \mathrm{a}$ ) which desorbed at
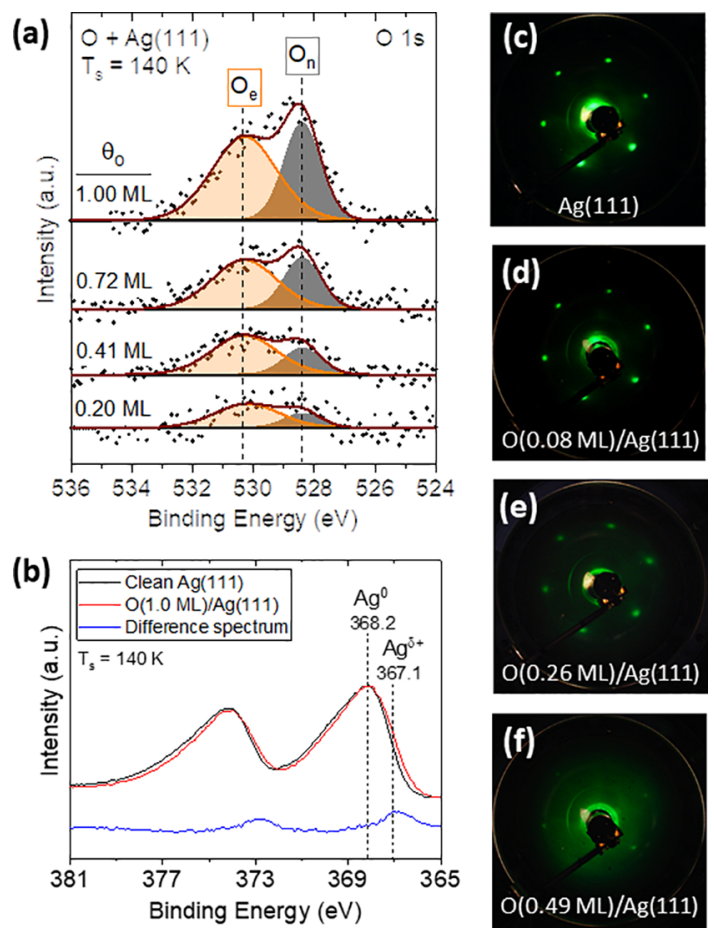

Figure 2. Atomic oxygen species can accommodate on $\mathrm{Ag}(111)$ without a surface reconstruction at low oxygen coverages $\left(\theta_{\mathrm{O}}<0.08\right.$ $\mathrm{ML}$ ), whereas increasing the oxygen coverage yields surface reconstruction accompanied by $\mathrm{Ag}$ oxide formation. (a) $\mathrm{O}$ 1s region of the X-ray photoelectron spectra as a function of oxygen coverage on $\mathrm{Ag}(111)$ at $140 \mathrm{~K}$. The deconvoluted signals at $530.3 \mathrm{eV}$ (orange, FWHM $=2.5 \mathrm{eV}$ ) and $528.4 \mathrm{eV}$ (gray, FWHM $=1.4 \mathrm{eV}$ ) are attributed to the electrophilic $\left(\mathrm{O}_{\mathrm{e}}\right)$ and nucleophilic $\left(\mathrm{O}_{\mathrm{n}}\right)$ oxygen species, respectively. (b) Ag 3d photoelectron spectra of clean (black) and 1.0 ML of oxygen-containing (red) $\mathrm{Ag}(111)$. Peak assignments: $368.2 \mathrm{eV}$ metallic silver $\left(\mathrm{Ag}^{0}\right), 367.1 \mathrm{eV} \mathrm{Ag}$ oxide $\left(\mathrm{Ag}^{\delta+}\right)$. The difference spectrum (blue) is given for better visualization of the $\mathrm{Ag}$ oxide peaks. LEED images of (c) clean and oxygen-containing $\mathrm{Ag}(111)$ obtained after (d) 0.08, (e) 0.26, and (f) $0.49 \mathrm{ML}$ of oxygen accumulation at $140 \mathrm{~K}$. (Beam energy: $\sim 70 \mathrm{eV}$.)

$350 \mathrm{~K}$. In addition to formaldehyde production, a weak $\mathrm{CO}_{2}$ desorption signal was also observed at $365 \mathrm{~K}$ (Figure $2 \mathrm{~b}$ ) for oxygen coverages $\left(\theta_{\mathrm{O}}\right)$ of 0.04 and $0.08 \mathrm{ML}$, indicating only a limited extent of total oxidation. However, the $\mathrm{CO}_{2}$ signal intensity increased with increasing oxygen coverage (i.e., $\theta_{\mathrm{O}}>$ $0.08 \mathrm{ML})$.

Additional quantitative information was extracted from the current TPRS results, revealing the variations in catalytic selectivity (Figure 1c) and catalytic conversion (Figure 1d) as a function of oxygen coverage. The TPRS results shown in Figure $1 \mathrm{c}, \mathrm{d}$ clearly indicate that catalytic selectivity and activity of the $\operatorname{Ag}(111)$ surface change drastically as a function of oxygen coverage for identical methanol exposures and identical dosing temperatures. While $\theta_{\mathrm{O}} \leq 0.08 \mathrm{ML}$ favors the SCO of methanol to formaldehyde with an enhanced formaldehyde selectivity that can reach up to $93 \% ; \theta_{\mathrm{O}} \geq 0.26 \mathrm{ML}$ promotes the total oxidation pathway by boosting the $\mathrm{CO}_{2}$ selectivity to $74 \%$ at $\theta_{\mathrm{O}}=0.49 \mathrm{ML}$. As shown in Figure $1 \mathrm{~d}$, the combined total amount of formaldehyde and $\mathrm{CO}_{2}$ production also increases by $c a .375 \%$ from $\theta_{\mathrm{O}}=0.04 \mathrm{ML}$ to $\theta_{\mathrm{O}}=0.26 \mathrm{ML}$, followed by some decrease at $\theta_{\mathrm{O}}=0.49 \mathrm{ML}$. Thus, it is apparent that a trade-off exists between the selectivity and total catalytic conversion of methanol. Accordingly, while formaldehyde selectivity can be maximized at low surface oxygen coverages, maximum methanol conversion is obtained at higher oxygen coverages.

One of the important aspects of the reactivity results shown in Figure 1a is the fact that increasing oxygen coverage not only alters the formaldehyde yield but also modifies its desorption kinetics noticeably. Another formaldehyde desorption feature at $282 \mathrm{~K}$ was obtained for $\theta_{\mathrm{O}}=0.26$ in addition to the existing formaldehyde signal at $350 \mathrm{~K}$; while the $350 \mathrm{~K}$ peak disappears for $\theta_{\mathrm{O}}=0.49$. Based on these experimental observations illustrating different reactivity trends of methanol on oxygen-containing silver surfaces, we hypothesize that the observed reactivity trends originate from the following causes: (a) differences in the electronic nature of the oxygen species generated on $\operatorname{Ag}(111)$, (b) variations in surface morphology of the $\mathrm{Ag}(111)$ model catalyst, and (c) relative adsorption energies and adsorption geometries of the generated intermediates or products during the methanol oxidation reaction at various oxygen coverages. We will address and corroborate each of these points in the following sections.

Electronic Nature of Oxygen Species on Ag(111). In an attempt to shed light on the chemical and electronic nature of the oxygen species formed on $\mathrm{Ag}(111)$ as a function of oxygen coverage, the XPS spectra of clean and oxygen covered $\operatorname{Ag}(111)$ surfaces were obtained by exposing the $\operatorname{Ag}(111)$ crystal to different exposures of ozone at $140 \mathrm{~K}$. Based on the corresponding $\mathrm{O} 1 \mathrm{~s}$ binding energy (B.E.) values, the electrophilic oxygen $\left(\mathrm{O}_{\mathrm{e}}\right)$ species $(530.3 \mathrm{eV})$ were observed to form on the $\operatorname{Ag}(111)$ surface at low oxygen coverages (i.e., $\left.\theta_{\mathrm{O}}=0.20 \mathrm{ML}\right)$, while the nucleophilic oxygen $\left(\mathrm{O}_{\mathrm{n}}\right)_{\text {species }}$ $(528.4 \mathrm{eV})$ were dominant at higher coverages as a result of silver oxide formation (Figure 2a). These assignments are in good accordance with the former studies which reported the $\mathrm{O}$ 1s B.E. values for $\mathrm{O}_{\mathrm{e}}$ within $530.0-530.5 \mathrm{eV}$ on silver ${ }^{16-18,26,40}$ and $528.1-528.5 \mathrm{eV}$ for $\mathrm{O}_{\mathrm{n}}$ of silver oxide films with $p(4 \times 4)$, $p(3 \times 5 r 3)$ rect, or $p(4 \times 5 r 3)$ rect structures. ${ }^{8,13,15,18}$

Figure $2 \mathrm{a}$ shows that upon increasing the oxygen surface coverage from 0.20 to $1.00 \mathrm{ML}$, the integrated XPS signals for $\mathrm{O}_{e}$ and $\mathrm{O}_{n}$ species increase by a factor of 4 and 8 , respectively. Two times greater boost in the $\mathrm{O}_{n}$ signal as opposed to that of $\mathrm{O}_{\mathrm{e}}$ provides evidence that high oxygen coverages induce silver oxide formation (along with surface reconstruction as discussed below) even at temperatures as low as $140 \mathrm{~K}$. Based on the former studies in the literature, the growing signal at $530.3 \mathrm{eV}$ for $\theta_{\mathrm{O}}>0.4 \mathrm{ML}$ can also be attributed to the silver oxide formation because the $\mathrm{O}$ 1s signal for the multilayer (bulk-like) silver oxide species (accompanied by the formation of subsurface oxygen) appears at a similar B.E. to 
(a) Unreconstructed $\mathrm{Ag}$ (111) Surface

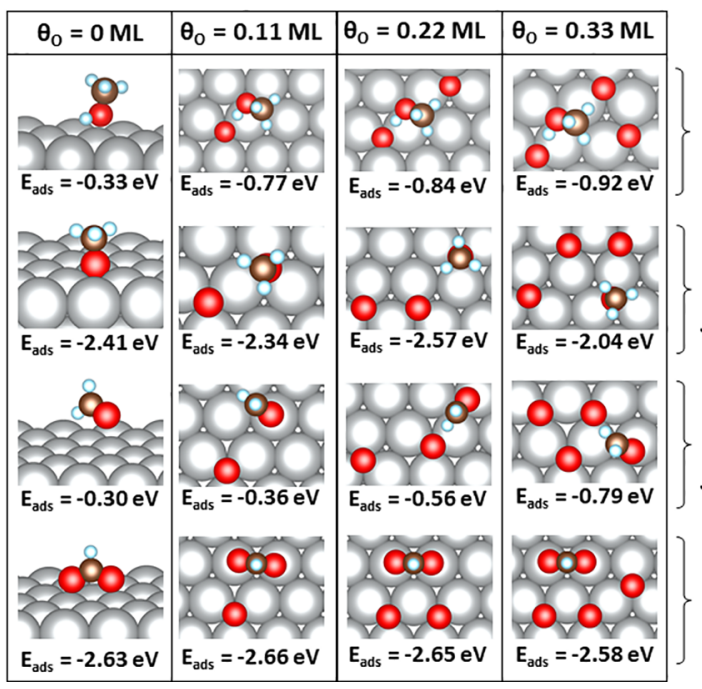

(b) Reconstructed $\mathrm{p}(4 \times 4)-\mathrm{O}(0.375 \mathrm{ML}) / \mathrm{Ag}(111)$ Surface

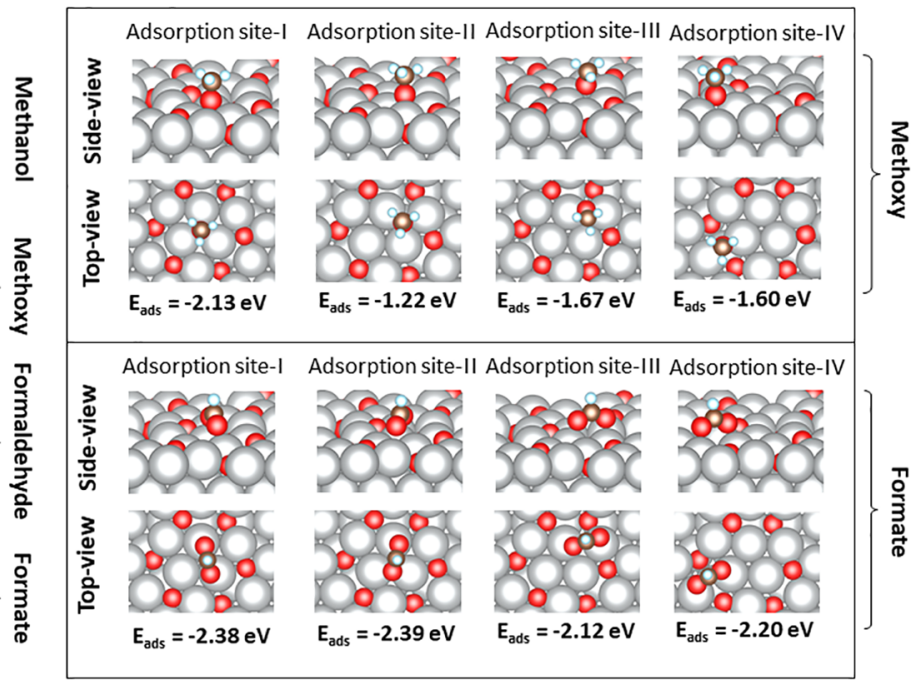

Figure 3. Optimized adsorption sites and their corresponding adsorption energies calculated via DFT computational models for different adsorbates on (a) clean $\mathrm{Ag}(111)$ and unreconstructed $\mathrm{O} / \mathrm{Ag}(111)$ and (b) reconstructed $p(4 \times 4)-\mathrm{O}(0.375 \mathrm{ML}) / \mathrm{Ag}(111)$ surface.

the $\mathrm{O}_{\mathrm{e}}$ species. $^{18,23,56}$ Therefore, it is likely that threedimensional silver oxide growth also contributes to the signal at $530.3 \mathrm{eV}$. Silver oxide formation is also consistent with the currently observed $-1.1 \mathrm{eV}$ core-level shift of the $\mathrm{Ag} 3 \mathrm{~d}$ signal with respect to that of the metallic silver signal (Figure $2 b$ ).

It is worth mentioning that another type of atomic oxygen on unreconstructed $\operatorname{Ag}(111)$ surfaces with a characteristic $\mathrm{O}$ 1s signal at $527.9 \mathrm{eV}$ was also reported in the literature at very low oxygen coverages $\left(\theta_{\mathrm{O}}<0.04 \mathrm{ML}\right) .^{22,33}$ Due to the detection limit of the currently utilized photoelectron detector, in the current work, the lowest oxygen coverage yielding a reliable $\mathrm{O}$ 1s signal was $0.20 \mathrm{ML}$. Thus, the presence of such minority species in the currently presented XPS data at low coverages (e.g., <0.20 ML) cannot be ruled out.

Morphology of the Oxygen-Containing $\mathrm{Ag}(111)$ Surfaces. The current LEED results (Figure $2 c-f$ ) verified that silver oxide formation and surface reconstruction events were relatively insignificant for low oxygen coverages at $140 \mathrm{~K}$. A sharp $(1 \times 1)$ LEED pattern that is characteristic of a clean $\mathrm{Ag}(111)$ surface was obtained for the $\mathrm{O}(0.08 \mathrm{ML}) / \mathrm{Ag}(111)$ surface at $140 \mathrm{~K}$ (Figure $2 \mathrm{~d}$ ), indicating the lack of (or negligible) surface reconstruction at this oxygen coverage. XPS results shown in Figure 2a also provides additional evidence for negligible $\mathrm{Ag}$ oxide formation at low oxygen coverages. In contrast, higher oxygen coverages (i.e., $\theta_{\mathrm{O}}>0.08 \mathrm{ML}$ ) on $\mathrm{Ag}(111)$-induced surface reconstruction due to silver oxide formation is evident by the diffuse $(1 \times 1)$ LEED pattern obtained for $\theta_{\mathrm{O}}=0.26 \mathrm{ML}$ on $\mathrm{Ag}(111)$ at $140 \mathrm{~K}$ (Figure 2e). A further increase in the oxygen coverage to $0.49 \mathrm{ML}$ boosted the surface corrugation and reconstruction, resulting in the complete disappearance of the LEED pattern (Figure $2 \mathrm{f}$ ). It is worth mentioning that the $0.49 \mathrm{ML}$ oxygen coverage was sufficient to generate a silver oxide surface which was also verified by annealing the $\mathrm{O}(0.49 \mathrm{ML}) / \operatorname{Ag}(111)$ surface originally prepared at $140-450 \mathrm{~K}$ in UHV (to improve ordering). Such a protocol revealed the formation of ordered silver oxide domains [i.e., $c(4 \times 8)$ structure] with characteristic and well-defined LEED patterns which were discussed in one of our former reports. ${ }^{35}$
Our findings demonstrate that oxygen accumulation on $\operatorname{Ag}(111)$ by ozone exposure resulted in surface structures that are comparable to the existing studies in the literature utilizing different oxygen delivery methods. Former scanning tunneling microscopy studies showed that for low oxygen coverages $\left(\theta_{\mathrm{O}}\right.$ $<0.05 \mathrm{ML})$, oxygen atoms were randomly located on $\operatorname{Ag}(111)$ without a surface reconstruction, while at higher oxygen coverages $\left(\theta_{\mathrm{O}}>0.05 \mathrm{ML}\right)$, silver oxide domains coexisted with unreconstructed $\operatorname{Ag}(111)$ regions. $^{13,47}$ Very high oxygen coverages $\left(\theta_{\mathrm{O}}>0.8 \mathrm{ML}\right)$ on $\mathrm{Ag}(111)$ led to bulk-oxide formation. ${ }^{23}$

In light of the XPS and LEED data shown in Figure 2, TPRS reactivity trends shown in Figure 1a can be discussed in more depth. It can be argued that for $\theta_{\mathrm{O}} \leq 0.08 \mathrm{ML}, \mathrm{O}_{\mathrm{e}}$ species are the prevalent species on the unreconstructed $\operatorname{Ag}(111)$ surface catalyzing high-temperature formaldehyde production at 350 $\mathrm{K}$, while $\mathrm{O}_{\mathrm{n}}$ species exist as minority species at these coverages promoting the formation of only minuscule amounts of $\mathrm{CO}_{2}$ at $370 \mathrm{~K}$. On the other hand, increasing oxygen coverage (i.e., for $\theta_{\mathrm{O}}=0.26 \mathrm{ML}$ ) and the emergence of $\mathrm{O}_{\mathrm{n}}$ species (initiating the growth of the $\mathrm{Ag}$ oxide overlayer) result in the observation of both the low-temperature formaldehyde production at $285 \mathrm{~K}$, as well as the formation of surging amounts of $\mathrm{CO}_{2}$ at $370 \mathrm{~K}$. At the highest oxygen coverage studied in the current TPRS experiments $\left(\theta_{\mathrm{O}}=0.49 \mathrm{ML}\right)$, the $\mathrm{Ag}$ oxide layer which predominantly comprised $\mathrm{O}_{\mathrm{n}}$ species, almost totally suppresses the high-temperature formaldehyde production at $350 \mathrm{~K}$, facilitating low-temperature formaldehyde production at 285 $\mathrm{K}$, while also enhancing $\mathrm{CO}_{2}$ production. Note that this particular oxygen coverage $\left(\theta_{\mathrm{O}}=0.49 \mathrm{ML}\right)$ not only significantly boosts the $\mathrm{CO}_{2}$ production but also lowers the $\mathrm{CO}_{2}$ formation temperatures to $350-310 \mathrm{~K}$. A former study reported that formaldehyde desorption occurred at $290 \mathrm{~K}$ for methanol reaction on the commonly observed reconstructed $p(4 \times 4)$ Ag oxide overlayer on $\operatorname{Ag}(111) .{ }^{44}$ Thus, the new formaldehyde desorption feature shown in Figure 1a at $282 \mathrm{~K}$ can be readily attributed to the methanol activation on the reconstructed $\mathrm{Ag}$ oxide overlayer.

Relative Stabilities and Adsorption Geometries of the Intermediates and Products. Optimized adsorption 
geometries and the adsorption energies of selected species (i.e., methanol, methoxy, formaldehyde, and formate) acting as reactants, intermediates, or products in the methanol oxidation were investigated using DFT computational modeling on the oxygen-containing unreconstructed $\operatorname{Ag}(111)$ surface as a function of oxygen coverage (Figure $3 \mathrm{a}$ ) and on the reconstructed $p(4 \times 4)-\mathrm{O}(0.375 \mathrm{ML}) / \mathrm{Ag}(111)$ surface (Figure $3 \mathrm{~b}$ ). Due to the repulsive interaction between oxygen adatoms that destabilize the surface at high coverages, we only report results on the $\mathrm{O} / \mathrm{Ag}(111)$ surface as shown in Figure 3a for oxygen coverages up to $0.33 \mathrm{ML}$. Methanol and formaldehyde bind to the clean surface only through weak van der Waals forces, as evidenced by the low adsorption energies. However, as the concentration of $\mathrm{O}$ atoms increases, there is a marked increase in the corresponding adsorption energies of both species due to the attractive interaction between the $\mathrm{O}$ atoms on the surface and the $\mathrm{H}$ atoms of the molecules via hydrogen bonding. Methoxy and formate, on the other hand, are already adsorbed strongly onto the clean $\mathrm{Ag}(111)$ surface. While methoxy stability is appreciably affected by the presence of surface oxygen species, the adsorption energy of formate species is relatively weakly altered by the oxygen coverage variations.

In contrast to the $\mathrm{O} / \operatorname{Ag}(111)$ surfaces, methoxy species display widely varying adsorption energies on the reconstructed $p(4 \times 4)-\mathrm{O} / \mathrm{Ag}(111)$ surface, indicating a much broader assortment of adsorption geometries (Figure $3 \mathrm{~b}$ ). While the most favorable methoxy geometry yields similar adsorption energy on the $\mathrm{O} / \mathrm{Ag}(111)$ and $p(4 \times 4)-\mathrm{O} /$ $\mathrm{Ag}(111)$ surfaces at a comparable oxygen coverage (i.e., 2.04 $\mathrm{eV}$ at $\theta_{\mathrm{O}}=0.33 \mathrm{ML}$ and $2.13 \mathrm{eV}$ at $\theta_{\mathrm{O}}=0.375 \mathrm{ML}$, respectively), the reconstructed $\mathrm{Ag}$ oxide surface provides multiple adsorption sites for methoxy species, yielding an adsorption energy range between 1.22 and $2.13 \mathrm{eV}$. Formate adsorption, on the other hand, proves to be relatively independent of the silver surface structure and the adsorbate environment. Formate, the species with the highest adsorption energy on both surfaces, is found to be exclusively in the bidentate adsorption geometry. These findings suggest that adsorption energy and thermal stability of both methoxy and formate intermediates are lower for the Ag oxide overlayers on the $\operatorname{Ag}(111)$ surfaces. Overall, the results presented in Figure 3 reveal that the investigated adsorbates can be ranked in the following increasing order of stability: formaldehyde on $\operatorname{Ag}(111)$ or unreconstructed $\mathrm{O} / \mathrm{Ag}(111)<$ methanol on $\operatorname{Ag}(111)$ or unreconstructed $\mathrm{O} / \mathrm{Ag}(111) \ll$ methoxy on reconstructed $\mathrm{Ag}$ oxide < methoxy on $\mathrm{Ag}(111)$ or on unreconstructed $\mathrm{O} / \mathrm{Ag}(111)<$ formate on reconstructed $\mathrm{Ag}$ oxide < formate on $\operatorname{Ag}(111)$ or unreconstructed $\mathrm{O} / \mathrm{Ag}(111)$.

The surface functional groups generated during the interaction of methanol with the clean or oxygen-containing $\mathrm{Ag}(111)$ model catalyst surface and their corresponding adsorption geometries were studied via IRAS (Figure 4). On the clean $\mathrm{Ag}(111)$ surface lacking any oxygen, methanol adsorbs in a molecular fashion (Figure $4 \mathrm{a}$ ) and desorbs from the surface at $<170 \mathrm{~K}$ (Figure S2) without being activated to methoxy species. Accordingly, characteristic vibrational signals of molecular methanol detected upon saturation methanol exposure (i.e., $0.03 \mathrm{~L}$ ) on the clean $\mathrm{Ag}(111)$ surface at $100 \mathrm{~K}$ (Figure $4 \mathrm{a}$ and Table 1 ) are in very good agreement with former TPD and IRAS results for methanol on pristine $\operatorname{Ag}(111){ }^{44,55}$

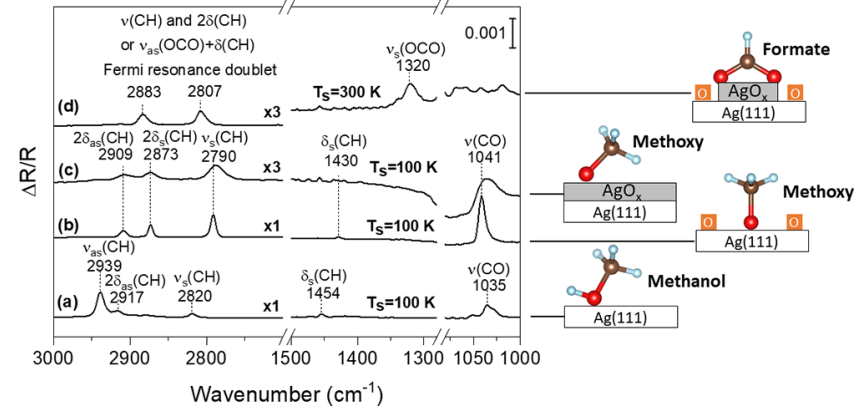

Figure 4. IR reflection absorption spectra obtained after methanol exposure at $100 \mathrm{~K}$ on (a) clean $\mathrm{Ag}(111)$, (b) unreconstructed $\mathrm{O}(0.04$ $\mathrm{ML}) / \mathrm{Ag}(111)$, and (c) reconstructed $\mathrm{Ag}$ oxide $\left(\theta_{\mathrm{O}}=0.40 \mathrm{ML}\right)$ surfaces. (d) Oxygen accumulation $\left(\theta_{\mathrm{O}}=0.10 \mathrm{ML}\right)$ at $140 \mathrm{~K}$ and subsequent methanol exposure at $300 \mathrm{~K}$ on $\mathrm{Ag}(111)$ yielding bridging bidentate formate species on the surface. The schematic representations of the adsorbed intermediates are given next to the corresponding spectra.

Table 1. IR Vibrational Frequencies and Vibrational Mode Assignments for Methanol, Methoxy, and Formate Species on $\operatorname{Ag}(111)^{a}, O / \operatorname{Ag}(111)^{b}$, and $\operatorname{Ag}$ Oxide Overlayers on $\operatorname{Ag}(111)^{c}$

\begin{tabular}{|c|c|c|c|c|}
\hline vibrational modes & methanol & methoxy & formate & ref \\
\hline$\nu(\mathrm{CO})$ & $1035^{\mathrm{a}}$ & $\begin{array}{l}1041^{\mathrm{b}} \\
1036^{\mathrm{c}}\end{array}$ & & 44 \\
\hline$\delta_{s}(\mathrm{CH})$ & $1454^{\mathrm{a}}$ & $1430^{\mathrm{b}}$ & & 44 \\
\hline$\nu_{\mathrm{s}}(\mathrm{CH})$ & $2820^{\mathrm{a}}$ & $\begin{array}{c}2790^{\mathrm{b}} \\
2788^{\mathrm{c}}\end{array}$ & & 44 \\
\hline $2 \delta_{\mathrm{s}}(\mathrm{CH})$ & & $2873^{\mathrm{b}, \mathrm{c}}$ & & 44 \\
\hline $2 \delta_{\mathrm{as}}(\mathrm{CH})$ & $2917^{\mathrm{a}}$ & $2909^{\mathrm{b}, \mathrm{c}}$ & & 44 \\
\hline$\nu_{\mathrm{as}}(\mathrm{CH})$ & $2939^{a}$ & & & 44 \\
\hline$\nu_{\mathrm{s}}(\mathrm{OCO})$ & & & $1320^{c}$ & 58 \\
\hline $\begin{array}{l}\text { fermi resonance doublet of } \nu(\mathrm{CH}) \\
\text { with } 2 \delta(\mathrm{CH}) \text { or } \\
\nu_{\text {as }}(\mathrm{OCO})+\delta(\mathrm{CH})\end{array}$ & & & $\begin{array}{c}2807^{c} \& \\
2883^{c}\end{array}$ & 58 \\
\hline
\end{tabular}

On the other hand, on oxygen-containing Ag surfaces (Figure $4 \mathrm{~b}, \mathrm{c}$ ), methanol can be readily activated to methoxy species via $\mathrm{O}-\mathrm{H}$ bond cleavage even at temperatures as low as $100 \mathrm{~K}$. While vibrational signatures of the generated methoxy species on the reconstructed $\mathrm{Ag}$ oxide overlayer (Figure $4 \mathrm{c}$ and Table 1) resemble that of the unreconstructed $\mathrm{O} / \mathrm{Ag}(111)$ surface (Figure $4 \mathrm{~b}$ and Table 1 ), the former surface reveals weaker and broader IRAS signals. The broadening of the IRAS signals, as shown in Figure 4c, can be explained by considering the increasing heterogeneity of the surface and the presence of nonuniform adsorption sites on the $\mathrm{Ag}$ oxide overlayer. Relatively weaker IRAS signal intensities, as shown in Figure $4 c$, can be attributed to multiple phenomena such as (i) decreasing IR absorption cross section of the adsorbed methoxy species due to the presence of the Ag oxide overlayer attenuating the image dipole strength in the underlying $\mathrm{Ag}(111)$ substrate $^{57}$ and (ii) tilting of the surface methoxy species. The latter is likely to occur because varying adsorption geometries of methoxy species were predicted by DFT calculations on the reconstructed $\mathrm{Ag}$ oxide surface (Figure 3b). Methoxy species adsorbed on the unreconstructed $\mathrm{O}(0.04$ $\mathrm{ML}) / \mathrm{Ag}(111)$ surface in an upright configuration (Figure $4 \mathrm{~b}$ ) yields a sharp and intense $\nu(\mathrm{CO})$ signal at $1041 \mathrm{~cm}^{-1}$. Weakening and broadening of this signal for the reconstructed Ag oxide $\left(\theta_{\mathrm{O}}=0.40 \mathrm{ML}\right)$ surface (Figure $4 \mathrm{c}$ ) suggests that the 
Scheme 1. Reactivity and Selectivity Trends of Methanol SCO on Unreconstructed O/Ag(111) and Reconstructed Ag Oxide Overlayer on $\operatorname{Ag}(111)$ Unreconstructed O/Ag(111) Surface
\[ \theta_{0} \leq 0.08 \mathrm{ML} \]

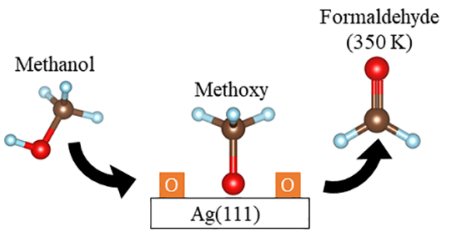

Reconstructed Ag Oxide Overlayer on Ag(111) $0.26 \mathrm{ML} \leq \theta_{0} \leq 0.49 \mathrm{ML}$

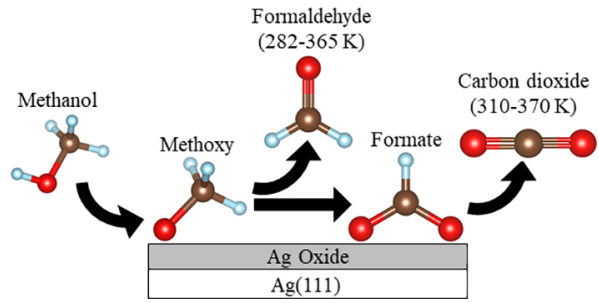

$\mathrm{C}-\mathrm{O}$ bond axis of methoxy species was oriented in a tilted fashion on the reconstructed Ag oxide surface. It is important to note that the upright versus tilted methoxy geometry may lead to significant changes in bond-breaking processes and alter the reaction pathways on reconstructed/unreconstructed silver model catalyst surfaces.

Marked differences in the relative thermal stabilities of the reaction intermediates can be considered as an indication of the presence of distinct reaction pathways. The current IRAS and TPRS results demonstrate that the stability of methoxy intermediates is significantly different on the reconstructed $\mathrm{Ag}$ oxide compared to that of the unreconstructed $\mathrm{O} / \mathrm{Ag}(111)$. For sufficiently low oxygen coverages (e.g., $\theta_{\mathrm{O}}=0.04 \mathrm{ML}$ ) precluding the formation of $\mathrm{Ag}$ oxide overlayers, methoxy species generated at $100 \mathrm{~K}$ are extremely stable and manage to survive on the surface in an intact manner even at $300 \mathrm{~K}$ (Figure S3). In contrast, methoxy decomposition and subsequent formaldehyde desorption occur below $300 \mathrm{~K}$ on the reconstructed Ag oxide surface (Figure 1a). This experimental observation is in good accordance with the relative adsorption energy trends estimated by the current DFT calculations (Figure 3), suggesting higher methoxy stability on unreconstructed $\mathrm{O} / \mathrm{Ag}(111)$.

In methanol SCO, formaldehyde production occurs via $\mathrm{C}-$ $\mathrm{H}$ bond rupture in the methoxy intermediate. Because adsorbed formaldehyde is extremely weakly bound to all of the currently investigated silver model catalyst surfaces (Figure 3 ), it can be safely argued that formaldehyde desorption occurs immediately after the $\mathrm{C}-\mathrm{H}$ bond activation in the adsorbed methoxy species and production of formaldehyde on the catalyst surface. Based on the desorption signals of formaldehyde as shown in Figure 1 a for $\mathrm{O}(0.26 \mathrm{ML}) / \mathrm{Ag}(111)$, the activation energy for methoxy decomposition on the reconstructed $\mathrm{Ag}$ oxide and unreconstructed $\mathrm{Ag}(111)$ can be estimated (assuming first-order kinetics ${ }^{58}$ and a pre-exponential factor of $10^{13} \mathrm{~s}^{-129}$ ) to be 75 and $94 \mathrm{~kJ} \mathrm{~mol}^{-1}$, respectively. The estimated activation energy difference of $19 \mathrm{~kJ} \mathrm{~mol}^{-1}$ indicates that $\mathrm{C}-\mathrm{H}$ bond rupture in methoxy species is kinetically favored on the reconstructed $\mathrm{Ag}$ oxide overlayers as opposed to the unreconstructed $\mathrm{O} / \mathrm{Ag}(111)$ surfaces. This is also consistent with the higher total methanol conversion on the reconstructed $\mathrm{Ag}$ oxide overlayers (Figure 1d). However, it is important to note that easier $\mathrm{C}-\mathrm{H}$ activation of the methoxy species and the associated lowered formaldehyde desorption temperature on the reconstructed Ag oxide overlayers does not lead to an enhanced formaldehyde selectivity (Figure 1a,c). This is probably because methoxy activation also leads to boosted formate production on the reconstructed $\mathrm{Ag}$ oxide overlayers, where these formate species can be further oxidized and generate the total oxidation product, $\mathrm{CO}_{2}$, as indicated in a prior study. ${ }^{44}$ Relatively high adsorption energies of formate species on the reconstructed Ag oxide overlayers (Figure $3 \mathrm{~b}$ ) also suggest a long surface residence time for formate species, allowing them to be totally oxidized to $\mathrm{CO}_{2}$ rather than desorbing as other partial oxidation products (e.g., esters). Along these lines, it can be argued that while methoxy species are more stable on the unreconstructed $\mathrm{O} / \mathrm{Ag}(111)$ surface, this surface is inefficient in formate production, which is an essential step that should occur before $\mathrm{CO}_{2}$ production.

Despite the high $\mathrm{CO}_{2}$ yield detected in the current TPRS experiments on the strongly oxidized $\mathrm{O}(0.49 \mathrm{ML}) / \mathrm{Ag}(111)$ (Figure 1), the lack of formate intermediates at $100 \mathrm{~K}$ in the IRAS data presented in Figure $4 \mathrm{c}$ indicated that formaldehyde production is kinetically hindered at $100 \mathrm{~K}$, and further oxidation of methoxy species to formaldehyde occurred at a higher temperature (i.e., >100 K). Similarly, IRAS data show that the formate production rate was also low on unreconstructed $\mathrm{O}(0.04 \mathrm{ML}) / \mathrm{Ag}(111)$ at $100 \mathrm{~K}$ (Figure $4 \mathrm{~b})$, leading to the predominance of methoxy species on this surface. Thus, we infer that $\mathrm{C}-\mathrm{H}$ bond rupture in methoxy yielding formaldehyde/formate is a kinetically hindered process, and formate intermediates could be generated via methanol exposure only at a temperature high enough to overcome the associated kinetic barrier.

Along these lines, formate production was readily achieved on $\mathrm{O}(0.10 \mathrm{ML}) / \mathrm{Ag}(111)$ at $300 \mathrm{~K}$ (Figure $4 \mathrm{~d}$ ). Figure $4 \mathrm{~d}$ indicates that the IRAS spectrum acquired after $0.03 \mathrm{~L}$ of methanol exposure at $300 \mathrm{~K}$ on the $\mathrm{O}(0.10 \mathrm{ML}) / \mathrm{Ag}(111)$ surface, followed by cooling to $140 \mathrm{~K}$, led to bridging bidentate formate species which adsorbed symmetrically on the surface via its oxygen atoms to two adjacent $\mathrm{Ag}$ atoms, where the $\mathrm{C}-$ $\mathrm{H}$ bond stayed orthogonal to the surface plane. ${ }^{59}$ These formate species facilitated the $\mathrm{CO}_{2}$ formation evidenced by the corresponding TPRS control experiment (Supporting Information Section 4, Figure S4) obtained after acquisition of the IRAS spectrum, as shown in Figure $4 \mathrm{~d}$. Thus, it can be argued that at sufficiently high surface oxygen coverages, the reconstructed silver oxide surface tends to react with formaldehyde at $300 \mathrm{~K}$ to produce formate, followed by complete oxidation to $\mathrm{CO}_{2}$.

The overall reactivity and selectivity trends of catalytic methanol oxidation on unreconstructed $\mathrm{O} / \mathrm{Ag}(111)$ and reconstructed $\mathrm{Ag}$ oxide overlayer on $\operatorname{Ag}(111)$ deduced from the current experimental and theoretical findings are summarized in Scheme 1. 


\section{CONCLUSIONS}

In the current work, we focused on the fundamental molecular origins of the catalytic selectivity in methanol oxidation over silver model catalyst surfaces using ozone as a uniquely efficient oxygen delivery vector. Particularly, we addressed three critical aspects governing catalytic activity and selectivity: (a) electronic nature of the oxygen species, (b) morphology of the silver model catalyst surfaces, and (c) stability of the intermediates and products formed during the methanol oxidation reaction on various silver model catalyst surfaces. Our results indicated that at least two different oxygen species existed on silver model catalyst surfaces, namely, electrophilic $\left(\mathrm{O}_{\mathrm{e}}\right)$ and nucleophilic $\left(\mathrm{O}_{\mathrm{n}}\right)$ oxygen. Surface oxygen coverages within $0.04 \mathrm{ML}<\theta_{\mathrm{O}} \leq 0.08 \mathrm{ML}$ favored $\mathrm{O}_{\mathrm{e}}$ species and mostly unreconstructed $\mathrm{O} / \mathrm{Ag}(111)$ surfaces, yielding boosted formaldehyde selectivity but low total methanol conversion. In contrast, elevated surface oxygen coverages such as $\theta_{\mathrm{O}} \geq 0.26$ ML predominantly generated $\mathrm{O}_{n}$ species, resulting in the reconstruction of the $\mathrm{Ag}(111)$ surface and formation of a $\mathrm{Ag}$ oxide overlayer, enhancing methanol conversion to $\mathrm{CO}_{2}$ while suppressing selectivity toward formaldehyde. Surface stability of the methoxy and formate intermediates was found to be lower for the reconstructed $\mathrm{Ag}$ oxide overlayers as compared to the unreconstructed $\mathrm{O} / \mathrm{Ag}(111)$ surfaces, where the former surfaces promoted lowering of the activation energies for $\mathrm{C}-\mathrm{H}$ bond scission in the methoxy intermediate and boosted $\mathrm{CO}_{2}$ production.

\section{ASSOCIATED CONTENT}

\section{S1 Supporting Information}

The Supporting Information is available free of charge at https://pubs.acs.org/doi/10.1021/acscatal.1c00344.

TPRS for methanol on $\mathrm{O} / \mathrm{Ag}(111)$; methanol adsorption on clean $\mathrm{Ag}(111)$; IR spectra of methoxy on $\mathrm{O}(0.04$ $\mathrm{ML}) / \mathrm{Ag}(111)$ at 100 and $300 \mathrm{~K}$; and temperatureprogrammed reaction of formate on $\mathrm{O}(0.10 \mathrm{ML}) /$ $\operatorname{Ag}(111)(\mathrm{PDF})$

\section{AUTHOR INFORMATION}

\section{Corresponding Author}

Emrah Ozensoy - Department of Chemistry and UNAMNational Nanotechnology Research Center, Institute of Materials Science and Nanotechnology, Bilkent University, 06800 Bilkent, Ankara, Turkey; 이이이.org/0000-00034352-3824; Email: ozensoy@fen.bilkent.edu.tr

\section{Authors}

Mustafa Karatok - Department of Chemistry, Bilkent University, 06800 Bilkent, Ankara, Turkey; 이이.org/ 0000-0001-5509-5463

Mehmet Gokhan Sensoy - Department of Physics, Recep Tayyip Erdogan University, 53100 Rize, Turkey; (1) orcid.org/0000-0003-4815-8061

Evgeny I. Vovk - Department of Chemistry, Bilkent University, 06800 Bilkent, Ankara, Turkey; (1) orcid.org/ 0000-0001-9340-0027

Hande Ustunel - Department of Physics, Middle East Technical University, 06800 Ankara, Turkey; (o orcid.org/ 0000-0003-0307-9036

Daniele Toffoli - Dipartimento di Scienze Chimiche e Farmaceutiche, Universita degli Studi di Trieste, 34127 Trieste, Italy; ○ orcid.org/0000-0002-8225-6119
Complete contact information is available at:

https://pubs.acs.org/10.1021/acscatal.1c00344

\section{Notes}

The authors declare no competing financial interest.

\section{ACKNOWLEDGMENTS}

The authors acknowledge the financial support from the Scientific and Technological Research Council of Turkey (TUBITAK) (Project Code: 112T589). E.O. acknowledges the scientific collaboration with the TARLA project funded by the Republic of Turkey Presidential Directorate of Strategy and Budget (project code: 2006K12-827). The authors also acknowledge Prof. Mehmet Erbudak (ETH Zurich) for his invaluable assistance with the UHV experimental setup and Mr. Mete Duman (UNAM) for his assistance with the design and production of the technical graphics.

\section{REFERENCES}

(1) Ebsdat, S. I. R.; Mayer, D. Ethylene Oxide. Ullmann's Encyclopedia of Industrial Chemistry; Wiley-VCH: Weinheim, 2012; Vol. 13, pp 547-572.

(2) Franz, A. W.; Kronemayer, H.; Pfeiffer, D.; Pilz, R. D.; Reuss, G.; Disteldorf, W.; Gamer, A. O.; Hilt, A. Formaldehyde. Ullmann's Encyclopedia of Industrial Chemistry; Wiley-VCH: Weinheim, 2016; pp $1-34$.

(3) Kowatsch, S. Formaldehyde. Phenolic Resins: A Century of Progress; Springer: Berlin, Heidelberg, 2010; pp 26-40.

(4) Millar, G. J.; Collins, M. Industrial Production of Formaldehyde Using Polycrystalline Silver Catalyst. Ind. Eng. Chem. Res. 2017, 56, 9247-9265.

(5) Pu, T.; Tian, H.; Ford, M. E.; Rangarajan, S.; Wachs, I. E. Overview of Selective Oxidation of Ethylene to Ethylene Oxide by $\mathrm{Ag}$ Catalysts. ACS Catal. 2019, 9, 10727-10750.

(6) Aljama, H.; Yoo, J. S.; Nørskov, J. K.; Abild-Pedersen, F.; Studt, F. Methanol Partial Oxidation on $\mathrm{Ag}(111)$ from First Principles. ChemCatChem 2016, 8, 3621-3625.

(7) Jones, T. E.; Wyrwich, R.; Böcklein, S.; Carbonio, E. A.; Greiner, M. T.; Klyushin, A. Y.; Moritz, W.; Locatelli, A.; Menteş, T. O.; Niño, M. A.; et al. The Selective Species in Ethylene Epoxidation on Silver. ACS Catal. 2018, 8, 3844-3852.

(8) Heine, C.; Eren, B.; Lechner, B. A. J.; Salmeron, M. A Study of the $\mathrm{O} / \mathrm{Ag}(111)$ System with Scanning Tunneling Microscopy and XRay Photoelectron Spectroscopy at Ambient Pressures. Surf. Sci. 2016, 652, 51-57.

(9) Derouin, J.; Farber, R. G.; Turano, M. E.; Iski, E. V.; Killelea, D. $\mathrm{R}$. Thermally Selective Formation of Subsurface Oxygen in $\mathrm{Ag}(111)$ and Consequent Surface Structure. ACS Catal. 2016, 6, 4640-4646.

(10) Grant, R. B.; Lambert, R. M. Basic Studies of the Oxygen Surface Chemistry of Silver: Chemisorbed Atomic and Molecular Species on Pure $\operatorname{Ag}(111)$. Surf. Sci. 1984, 146, 256-268.

(11) Campbell, C. T. Atomic and Molecular Oxygen Adsorption on $\operatorname{Ag}(111)$. Surf. Sci. 1985, 157, 43-60.

(12) Bao, X.; Muhler, M.; Schedel-Niedrig, T.; Schlögl, R. Interaction of Oxygen with Silver at High Temperature and Atmospheric Pressure: A Spectroscopic and Structural Analysis of a Strongly Bound Surface Species. Phys. Rev. B: Condens. Matter Mater. Phys. 1996, 54, 2249-2262.

(13) Schnadt, J.; Knudsen, J.; Hu, X. L.; Michaelides, A.; Vang, R. T.; Reuter, K.; Li, Z.; Lægsgaard, E.; Scheffler, M.; Besenbacher, F. Experimental and Theoretical Study of Oxygen Adsorption Structures on $\mathrm{Ag}(111)$. Phys. Rev. B: Condens. Matter Mater. Phys. 2009, 80, 075424 .

(14) Derouin, J.; Farber, R. G.; Heslop, S. L.; Killelea, D. R. Formation of Surface Oxides and $\mathrm{Ag}_{2} \mathrm{O}$ Thin Films with Atomic Oxygen on $\mathrm{Ag}(111)$. Surf. Sci. 2015, 641, L1-L4. 
(15) Reichelt, R.; Günther, S.; Rößler, M.; Wintterlin, J.; Kubias, B.; Jakobi, B.; Schlögl, R. High-Pressure STM of the Interaction of Oxygen with $\operatorname{Ag}(111)$. Phys. Chem. Chem. Phys. 2007, 9, 3590-3599.

(16) Bukhtiyarov, V. I.; Hävecker, M.; Kaichev, V. V.; Knop-Gericke, A.; Mayer, R. W.; Schlögl, R. Atomic Oxygen Species on Silver: Photoelectron Spectroscopy and X-Ray Absorption Studies. Phys. Rev. B: Condens. Matter Mater. Phys. 2003, 67, 235422.

(17) Bukhtiyarov, V. I.; Kaichev, V. V.; Prosvirin, I. P. Oxygen Adsorption on $\operatorname{Ag}(111)$ : X-Ray Photoelectron Spectroscopy (XPS), Angular Dependent X-Ray Photoelectron Spectroscopy (ADXPS) and Temperature-Programmed Desorption (TPD) Studies. J. Chem. Phys. 1999, 111, 2169.

(18) Rocha, T. C. R.; Oestereich, A.; Demidov, D. V.; Hävecker, M.; Zafeiratos, S.; Weinberg, G.; Bukhtiyarov, V. I.; Knop-Gericke, A.; Schlögl, R. The Silver-Oxygen System in Catalysis: New Insights by near Ambient Pressure X-Ray Photoelectron Spectroscopy. Phys. Chem. Chem. Phys. 2012, 14, 4554-4564.

(19) Li, W.-X.; Stampfl, C.; Scheffler, M. Subsurface Oxygen and Surface Oxide Formation at $\mathrm{Ag}(111)$ : A Density-Functional Theory Investigation. Phys. Rev. B: Condens. Matter Mater. Phys. 2003, 67, 045408.

(20) Li, W.-X.; Stampfl, C.; Scheffler, M. Why Is a Noble Metal Catalytically Active? The Role of the O-Ag Interaction in the Function of Silver as an Oxidation Catalyst. Phys. Rev. Lett. 2003, 90, 256102.

(21) Michaelides, A.; Reuter, K.; Scheffler, M. When Seeing Is Not Believing: Oxygen on $\mathrm{Ag}$ (111), a Simple Adsorption System? J. Vac. Sci. Technol., A 2005, 23, 1487-1497.

(22) Jones, T. E.; Rocha, T. C. R.; Knop-Gericke, A.; Stampfl, C.; Schlögl, R.; Piccinin, S. Thermodynamic and Spectroscopic Properties of Oxygen on Silver under an Oxygen Atmosphere. Phys. Chem. Chem. Phys. 2015, 17, 9288-9312.

(23) Martin, N. M.; Klacar, S.; Grönbeck, H.; Knudsen, J.; Schnadt, J.; Blomberg, S.; Gustafson, J.; Lundgren, E. High-Coverage OxygenInduced Surface Structures on $\mathrm{Ag}(111)$. J. Phys. Chem. C 2014, 118, 15324-15331.

(24) Li, W. X.; Stampfl, C.; Scheffler, M. Oxygen Adsorption on $\mathrm{Ag}(111)$ : A Density-Functional Theory Investigation. Phys. Rev. B: Condens. Matter Mater. Phys. 2002, 65, 075407.

(25) Bukhtiyarov, V. I.; Boronin, A. I.; Savchenko, V. I. Stages in the Modification of a Silver Surface for Catalysis of the Partial Oxidation of Ethylene. I. Action of Oxygen. J. Catal. 1994, 150, 262-267.

(26) Günther, S.; Böcklein, S.; Wintterlin, J.; Niño, M. A.; Menteş, T. O.; Locatelli, A. Locating Catalytically Active Oxygen on $\operatorname{Ag}(111)$ A Spectromicroscopy Study. ChemCatChem 2013, 5, 3342-3350.

(27) Bukhtiyarov, V. I.; Hävecker, M.; Kaichev, V. V.; Knop-Gericke, A.; Mayer, R. W.; Schlögl, R. X-Ray Absorption and Photoemission Studies of the Active Oxygen for Ethylene Epoxidation over Silver. Catal. Lett. 2001, 74, 121-125.

(28) Felter, T. E.; Weinberg, W. H.; Lastushkina, G. Y.; Zhdan, P. A.; Boreskov, G. K.; Hrbek, J. The Adsorption of Methanol on $\mathrm{Ag}(111)$ and Its Reaction with Preadsorbed Oxygen. Appl. Surf. Sci. 1983, 16, 351-364.

(29) Wachs, I. E.; Madix, R. J. The Oxidation of Methanol on a Silver (110) Catalyst. Surf. Sci. 1978, 76, 531-558.

(30) Bao, X.; Muhler, M.; Pettinger, B.; Schlögl, R.; Ertl, G. On the Nature of the Active State of Silver During Catalytic-Oxidation of Methanol. Catal. Lett. 1993, 22, 215-225.

(31) Waterhouse, G. I. N.; Bowmaker, G. A.; Metson, J. B. Mechanism and Active Sites for the Partial Oxidation of Methanol to Formaldehyde over an Electrolytic Silver Catalyst. Appl. Catal., A 2004, 265, 85-101.

(32) Montoya, A.; Haynes, B. S. Methanol and Methoxide Decomposition on Silver. J. Phys. Chem. C 2007, 111, 9867-9876.

(33) Carbonio, E. A.; Rocha, T. C. R.; Klyushin, A. Y.; Píš, I.; Magnano, E.; Nappini, S.; Piccinin, S.; Knop-Gericke, A.; Schlögl, R.; Jones, T. E. Are Multiple Oxygen Species Selective in Ethylene Epoxidation on Silver? Chem. Sci. 2018, 9, 990-998.
(34) Jones, T. E.; Rocha, T. C. R.; Knop-Gericke, A.; Stampfl, C.; Schlögl, R.; Piccinin, S. Insights into the Electronic Structure of the Oxygen Species Active in Alkene Epoxidation on Silver. ACS Catal. 2015, 5, 5846-5850.

(35) Karatok, M.; Vovk, E. I.; Koc, A. V.; Ozensoy, E. Selective Catalytic Ammonia Oxidation to Nitrogen by Atomic Oxygen Species on $\operatorname{Ag}(111)$. J. Phys. Chem. C 2017, 121, 22985-22994.

(36) Nagy, A.; Mestl, G.; Rühle, T.; Weinberg, G.; Schlögl, R. The Dynamic Restructuring of Electrolytic Silver during the Formaldehyde Synthesis Reaction. J. Catal. 1998, 179, 548-559.

(37) Andreasen, A.; Lynggaard, H.; Stegelmann, C.; Stoltze, P. A Microkinetic Model of the Methanol Oxidation over Silver. Surf. Sci. 2003, 544, 5-23.

(38) Zugic, B.; van Spronsen, M. A.; Heine, C.; Montemore, M. M.; Li, Y.; Zakharov, D. N.; Karakalos, S.; Lechner, B. A. J.; Crumlin, E.; Biener, M. M.; Frenkel, A. I.; Biener, J.; Stach, E. A.; Salmeron, M. B.; Kaxiras, E.; Madix, R. J.; Friend, C. M. Evolution of Steady-State Material Properties during Catalysis: Oxidative Coupling of Methanol over Nanoporous $\mathrm{Ag}_{0.03} \mathrm{Au}_{0.97}$. J. Catal. 2019, 380, 366-374.

(39) Zhang, Z.; Zandkarimi, B.; Alexandrova, A. N. Ensembles of Metastable States Govern Heterogeneous Catalysis on Dynamic Interfaces. Acc. Chem. Res. 2020, 53, 447-458.

(40) Böcklein, S.; Günther, S.; Wintterlin, J. High-Pressure Scanning Tunneling Microscopy of a Silver Surface during Catalytic Formation of Ethylene Oxide. Angew. Chem., Int. Ed. 2013, 52, 5518-5521.

(41) Nagy, A. J.; Mestl, G.; Herein, D.; Weinberg, G.; Kitzelmann, E.; Schlögl, R. The Correlation of Subsurface Oxygen Diffusion with Variations of Silver Morphology in the Silver-Oxygen System. J. Catal. 1999, 182, 417-429.

(42) Nagy, A.; Mestl, G. High Temperature Partial Oxidation Reactions over Silver Catalysts. Appl. Catal., A 1999, 188, 337-353.

(43) Wang, C.-B.; Deo, G.; Wachs, I. E. Interaction of Polycrystalline Silver with Oxygen, Water, Carbon Dioxide, Ethylene, and Methanol: In Situ Raman and Catalytic Studies. J. Phys. Chem. B 1999, 103, 5645-5656.

(44) Sim, W. S.; Gardner, P.; King, D. A. Structure and Reactivity of the Surface Methoxy Species on $\operatorname{Ag}(111)$. J. Phys. Chem. 1995, 99, $16002-16010$

(45) Saliba, N.; Parker, D. H.; Koel, B. E. Adsorption of Oxygen on $\mathrm{Au}(111)$ by Exposure to Ozone. Surf. Sci. 1998, 410, 270-282.

(46) Saliba, N. A.; Tsai, Y.-L.; Panja, C.; Koel, B. E. Oxidation of Pt (111) by Ozone $\left(\mathrm{O}_{3}\right)$ under UHV Conditions. Surf. Sci. 1999, 419, 79-88.

(47) Carlisle, C. I.; Fujimoto, T.; Sim, W. S.; King, D. A. Atomic Imaging of the Transition between Oxygen Chemisorption and Oxide Film Growth on $\operatorname{Ag}\{111\}$. Surf. Sci. 2000, 470, 15-31.

(48) Karatok, M.; Vovk, E. I.; Shah, A. A.; Turksoy, A.; Ozensoy, E. Acetaldehyde Partial Oxidation on the $\mathrm{Au}(111)$ Model Catalyst Surface: C-C Bond Activation and Formation of Methyl Acetate as an Oxidative Coupling Product. Surf. Sci. 2015, 641, 289-293.

(49) Schmid, M.; Reicho, A.; Stierle, A.; Costina, I.; Klikovits, J.; Kostelnik, P.; Dubay, O.; Kresse, G.; Gustafson, J.; Lundgren, E.; Andersen, J. N.; Dosch, H.; Varga, P. Structure of $\mathrm{Ag}(111)-\mathrm{p}(4 \mathrm{x} 4)-\mathrm{O}$ : No Silver Oxide. Phys. Rev. Lett. 2006, 96, 146102.

(50) Kresse, G.; Hafner, J. Ab Initio Molecular Dynamics for Liquid Metals. Phys. Rev. B: Condens. Matter Mater. Phys. 1993, 47, 558-561.

(51) Kresse, G.; Joubert, D. From Ultrasoft Pseudopotentials to the Projector Augmented-Wave Method. Phys. Rev. B: Condens. Matter Mater. Phys. 1999, 59, 1758-1775.

(52) Perdew, J. P.; Burke, K.; Ernzerhof, M. Generalized Gradient Approximation Made Simple. Phys. Rev. Lett. 1996, 77, 3865-3868.

(53) Tkatchenko, A.; Scheffler, M. Accurate Molecular van Der Waals Interactions from Ground-State Electron Density and FreeAtom Reference Data. Phys. Rev. Lett. 2009, 102, 073005.

(54) Monkhorst, H. J.; Pack, J. D. Special Points for Brillouin-Zone Integrations. Phys. Rev. B: Solid State 1976, 13, 5188-5192.

(55) Jenniskens, H. G.; Dorlandt, P. W. F.; Kadodwala, M. F.; Kleyn, A. W. The Adsorption of Methanol on $\mathrm{Ag}(111)$ Studied with TDS and XPS. Surf. Sci. 1996, 357-358, 624-628. 
(56) Pettinger, B.; Bao, X.; Wilcock, I. C.; Muhler, M.; Ertl, G. Surface-Enhanced Raman Scattering from Surface and Subsurface Oxygen Species at Microscopically Well-Defined Ag Surfaces. Phys. Rev. Lett. 1994, 72, 1561-1564.

(57) Hoffmann, F. M. Infrared Reflection-Absorption Spectroscopy of Adsorbed Molecules. Surf. Sci. Rep. 1983, 3, 107-192.

(58) Redhead, P. A. Thermal Desorption of Gases. Vacuum 1962, $12,203-211$.

(59) Sim, W. S.; Gardner, P.; King, D. A. Multiple Bonding Configurations of Adsorbed Formate on $\mathrm{Ag}\{111\}$. J. Phys. Chem. 1996, 100, 12509-12516. 